\title{
DEALING WITH THE EFFECTS OF RANDOM TIME DELAY AND DATA DROPOUTS IN NETWORKED CONTROL SYSTEMS THROUGH ROBUST CONTROL
}

\author{
Gorjan Nadžinski. Mile Stankovski, Ivan Gočev \\ Faculty of Electrical Engineering and Information Technologies, \\ "Ss. Cyril and Methodius" University in Skopje, \\ Rugjer Bošković bb, P.O. box 574, 1001 Skopje, Republic of Macedonia \\ milestk@feit.ukim.edu.mk
}

\begin{abstract}
A b s t r a c t: The concept of control over network is widely accepted and used in the world of automation, so the stability, safety, and robustness of the distributed and control systems are of key importance for their proper performance. Thus, it is essential to search for solutions of remote control problems like variable time-delay, data-loss, equipment malfunctions, and unauthorized network infiltrations. This paper gives an $\mathrm{H}_{\infty}$ robust control algorithm, which stabilizes a ZigBee networked control system in the presence of random delays, network overload, and data package loss.
\end{abstract}

Key words: networked control systems; robust control; $\mathrm{H}_{\infty}$ infinity control; data loss; random time delay; ZigBee

\section{СПРАВУВАЊЕ СО ЕФЕКТИТЕ ОД СЛУЧАЈНИ ДОЦНЕЊА И ГУБЕЊЕ ПОДАТОЧНИ ПАКЕТИ ВО ВМРЕЖЕНИТЕ КОНТРОЛНИ СИСТЕМИ ПРЕКУ РОБУСНО УПРАВУВАҢЕ}

\begin{abstract}
А п с т р а к т: Концептот на управување преку мрежа е широко распространет и често употребуван во модерната автоматика, па затоа стабилноста, безбедноста и робусноста на дистрибуираните системи на управување се од клучно значење за нивно правилно функционирање. Затоа е неопходно да се бараат решенија на најчестите проблеми кај ваквите системи, како што се случајните временски доцнења, загубата на податоци, неисправноста на опремата и неавторизираните упади. Овој труд презентира робустен алгоритам за $\mathrm{H}_{\infty}$ управување, кој стабилизира вмрежен систем на автоматско управување преку мрежата ZigBee во присуство на случајни доцнења, преоптовареност на мрежата и загуба на податочни пакети.
\end{abstract}

Клучни зборови: вмрежени системи на автоматско управување; робусно управување; $\mathrm{H}_{\infty}$ управување; загуба на податоци; случајни временски доцнења: ZigBee

\section{INTRODUCTION}

A networked control system (NCS) is a term used to describe systems where sensors, actuators, and controllers are interconnected with a shared communication network [1]. The studying of these systems represents an interdisciplinary activity, as it encompasses both control theory and telecommunication. Therefore, in order to guarantee the stability and the quality performance of NCSs, analysis and design methods based both on the network and the control parameters are required [1, 2].
The situation where all the elements of a system share a common medium contributes for many advantages NCSs have in modern industry automation; especially the fact that systems are now far more efficient, flexible and easier to maintain. However, it also causes a wide range of drawbacks, some of the more serious being the conflicts of network access scheduling, and the subsequent data dropouts and time delays which these conflicts induce. This paper tests a control algorithm which is meant to robustly stabilize a given NCS by modeling the random time-delays and data package dropouts and uncertainties and perturba- 
tions in the system, and by then setting the problem up as an $\mathrm{H}_{\infty}$ robust control problem and solving it. The system which will be used to test and simulate the algorithm on is a NCS where the communication network is based on the wireless ZigBee standard. ZigBee was chosen as it represents a standard with a growing popularity in industry and home automation.

The paper is organized as follows: firstly, a brief overview of NCS is given in Section 2, along with a survey on recent accomplishments in the field of control of NCS and dealing with delays, data dropouts, and scheduling conflicts; next, Section 3 will give a basic description of the ZigBee standard and a survey of its role in NCS; the design of the controller and the simulation results will be provided in Section 4, before Section 5 gives a conclusion and some ideas for future work.

\section{NETWORKED CONTROL SYSTEMS}

Networked control systems have long been an interesting research topic [1], [2], [3], [4]. Today they are widely used in industry and home automation, because NCSs provide flexibility and modularity, contributes for easier maintenance and adds redundancy to the entire control setup.

When all the components of a feedback control system are connected and communicating via a network which can be shared with other systems or entities, then this system can be classified as a networked control system (Fig. 1) [1]. In reality all connections between any two given system components, are established through some sort of network or medium. However, until recently modern control theory assumed that the exchange of signals, data, and information between the elements of a feedback control system, and the calculations inside the controller, take place instantaneously and without any delays or data losses. In reality, the emergence of large distributed systems and the growing complexity of control laws mean that the previous simplifications no longer hold. Networked control systems demand several previously unattended actions, such as modeling of the communication medium and its influence on the system, and taking into consideration the fact that signals travel in packages with a finite speed, and that sending, receiving, coding, and decoding of data takes time [3]. Therefore, occurrences such as random time delays, network access conflicts, and data dropouts have a significant impact on the NCS performance.

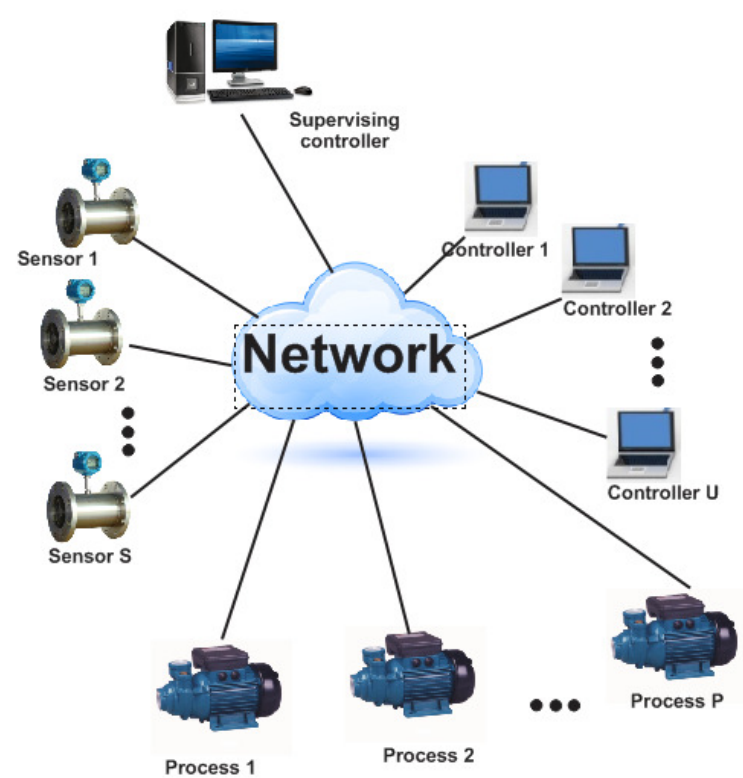

Fig. 1. Structure of a networked control system

The main efforts regarding NCS control are focused on dealing with the aforementioned problems. It has been generally agreed that the main issues which threaten the stability and the safety of NCS are network-induced delays, data loss, limited channel capacity, network security, and network access conflicts [1], [2]. There are three major approaches that are used for dealing with these issues [4]:

- the control-based approach explicitly takes into account the network characteristics and then considers the proper control methodologies for the given situation (i.e. the network is preexisting, and the controller is then derived);

- the network-based approach defines the control system independently from the network, and then states the network requirements accordingly (i.e. the system is preexisting, and suitable network parameters are then derived);

- the last approach represents a combination of the latter two, as it studies both the control and the network requirements in order to optimize the system.

The time delays in the networks occur due to the fact that the system shares the network with other elements and/or systems, so often the capacity of the network is overloaded. These networkinduced delays can be modeled as constant delays (with the help of a buffer), or as variable and stochastic delays. The delays can be roughly lumped into two groups: the delays from the sensor to the 
controller $\tau_{\mathrm{sc}}$ (the time that passes from the moment the plant output is sampled, to the moment the controller starts calculating the next value of the control signal), and the delays from the controller to the actuator $\tau_{\mathrm{ca}}$ (the time that passes from the moment the controller starts sending the data representing the control signal value, to the moment the actuator starts influencing the plant according to the sent signal). If we observe things on the physical level, we can expand to other types of delays, such as the waiting time delay $\tau_{\mathrm{W}}$ (the time spent in waiting for the network to be available for sending data), the frame time delay $\tau_{\mathrm{F}}$ (the time spent in framing the data packages on the transmitting side, and unpacking them at the receiving side), and the propagation delay $\tau_{P}$ (the time the data packages spend traveling to their destination). Of course, there exist many other network-induced delays, such as the ones caused by the network parameters and the communication protocol that is being used.

The choice of the network also has a significant influence on the time delays. If the NCS is connected with a cyclic service network (IEEE 802.4, IEEE 802.5, PROFIBUS), then the delays are deterministic and easy to incorporate into the system model; however, if the NCS is built on a random access network (Ethernet, CAN), then the delays are caused by the package collisions and are of a stochastic nature, which naturally makes them more difficult to model and to take into account.

Methods used to model the delays have ranged from conventional system identification tools [5], to using Markov chains [6], T-S fuzzy models [7], or ARMA models [8]. The compensation of the effects of this unwanted phenomenon has been done with many different approaches, such as: solving the problem as a LQG (Linear Quadratic Gaussian) problem [9]; modeling the delays as disturbances and posing the problem as a robust control problem, and thus trying to solve it with the respective existent tools [10]; introducing queues so as to represent the NCS as a time-invariant system [11]; using a state observer and a delay predictor and compensator, which relies on highly accurate modeling [12]; design of an event-based controller, which is therefore totally independent of the time delays [13].

Most recently, the framework for networked control systems has been extended to more approaches. These include but are not limited to [2]:

- quantization, which is motivated by the network capacity constraints;
- fault diagnosis, which is a process consisting of keeping track of system performance, and the detection, isolation, and identification of faults in the control loop;

- $\quad$ state estimation, which can be done by filtering (to estimate system states with noise), or by distributed data fusion (to improve the accuracy of the data by combining information from multiple network nodes);

- networked predictive control, which is based on general predictive control, but can refer to the system model or the network parameters (data package based predictive control, datadriven predictive control, etc.);

- cloud control, which merges the advantages of networked control system approaches and cloud computing.

Obviously, networked control systems play a significant role in automation and therefore the search for solutions of their most commonly occurring issues are of great interest.

\section{THE ZigBee STANDARD IN NCS}

The main reason for the growing popularity of wireless standards in industry automation is the increase in flexibility, effectiveness and range that is obtained when using a wireless network to implement a NCS. The ZigBee standard, developed by the IEEE workgroup 4 and the ZigBee Alliance at the beginning of the last decade, is a wireless communication standard specialized for low range, low cost, and long life Wireless Personal Area Networks. These characteristics make ZigBee and interesting candidate when considering a communication protocol for a NCS design [14].

The standard is based on the OSI model, but only contains the physical layer, the MAC sub layer, the network layer, and the application layer (user defined). The frequencies of operation are defined at $868 \mathrm{MHz}$ in Europe, at $915 \mathrm{MHz}$ in USA and Australia, and at $2.4 \mathrm{GHz}$ worldwide, and the modulation methods used are DSSS (Direct-sequence spread spectrum) for the lower, and O-QPSK (offset quadrature phase-shift keying) for the higher frequencies. The standard defines three types of devices: coordinators (only one per network, represents the root of the network and coordinates all communication and network parameters), routers (responsible for data routing and network extension), and end-devices (representing the interface to the field devices, such as sensors and 
actuators). The end-devices are active only for short intervals, enough to transfer data from the network to the process and/or vice-versa. This contributes to high efficiency and longer battery life of the communication modules. The most common network topologies are tree, star mesh network topology.

The ZigBee protocol supports two network access mechanisms: the non-beacon enabled mode, where a unslotted CSMA - CA (carrier sense multiple access with collision detection) is used, and the beacon enabled mode, where periodically emitted beacon signals coordinate the communication and the network access of the nodes. The latter method makes the communication more deterministic and also extends the battery life and lowers the duty cycle, as nodes are in sleep mode in between beacons.

As a wireless communication standard, lately ZigBee can often be found in many NCSs. Although its characteristics make it a somewhat preferable choice for a NCS standard, ZigBee NCSs still suffer from the same issues mentioned previously. A lot of research has gone into dealing with these problems specifically in ZigBee NCSs, more notably:

- Mouney, Juanole \& Calmettes give the lowest acceptable sampling rate in these systems as $6.3 \mathrm{~ms}$ [15];

- Koubaa, Alves, Song \& Nefzi [16] propose a slotted CSMA - CA mechanism in time sensitive applications;

- Rao \& Marandin [17] give an improved backoff time calculation algorithm;

- Sobrino \& Krishnakumar [18] define the black-burst network access mechanism;

- Umirov, Jeong \& Park [19] propose the introduction of a play-back buffer which would introduce a fixed and deterministic delay in the network.

\section{4. $\mathrm{H}_{\infty}$ CONTROLLER IMPLEMENTATION}

The proposed $\mathrm{H}_{\infty}$ robust controller was designed by Yue, Han \& Lam in [20]. It is used to stabilize an uncertain NCS, taking into account the effects of the network induced delays and the data dropout.

The authors represent the system with a continuous model with uncertainty, while at the same time modeling the delays and dropouts by introducing the sampling time and some discrete integer values in the model. The total time delay in every iteration is a time-varying function of the quantity of data-loss in the network, and its value is given both an upper and a lower positive bound. The robust controller design theorem by Yue, Han \& Lam states that a controller which stabilizes the system can be derived by solving a set of linear matrix inequalities given in [20]. The proof, which can also be found in [20], is based on the construction of a Lyapunov-Krasovskii functional and thus establishing the exponential stability criteria for the system, given by the said LMIs.

A controller as described above was designed for an unstable process (1) with further interference applied to the input (2), which was to be controlled and stabilized over a ZigBee network:

$$
\begin{gathered}
G(s)=\frac{0.1 s^{3}+1.1 s^{2}+0.975 s+0.225}{s^{3}+s^{2}-0.25 s-0.25} \\
w(t)=\left\{\begin{aligned}
0.3, & 2 s \leq t \leq 4 s \\
0, & \text { otherwise }
\end{aligned}\right.
\end{gathered}
$$

The entire system was simulated in the special Matlab NCS extension TrueTime [21]. The network consisted of three different nodes (Fig. 2). The sensor/actuator node sampled data from the process in regular intervals and sent it to the controller, or acted on the process after receiving the control signal value from the controller. The controller node calculated the control signal upon receiving the measured values from the sensor, and then sent it to the actuator. The interference node applied a random uniform noise across the entire network. The controller also randomly executed an empty (dummy) task with higher priority than the control task, in order to simulate network overload. All the data propagation throughout the network was subjected to uniform random transport delays ranged between $0.1 \mathrm{~s}$ and $0.5 \mathrm{~s}$ (that is 2.5 times the sampling rate in the worst case).

Different scenarios were tested by using the opportunities provided by the TrueTime simulator. Simulations were run with different values for: the error and data loss probabilities, the physical positions of the nodes, the transmit power and receiver signal threshold, and the percentage of reduced network capacity. Other vital parameters were also established: the data rate was a standard $250 \mathrm{kbps}$, the sampling period was set at $200 \mathrm{~ms}$, and the exponent of the path-loss function was set at 3.5, thus modeling air as the primary environment through which the radio waves travel. Also, the initial condition stated that in the beginning, the process output is $y=1.7$. 


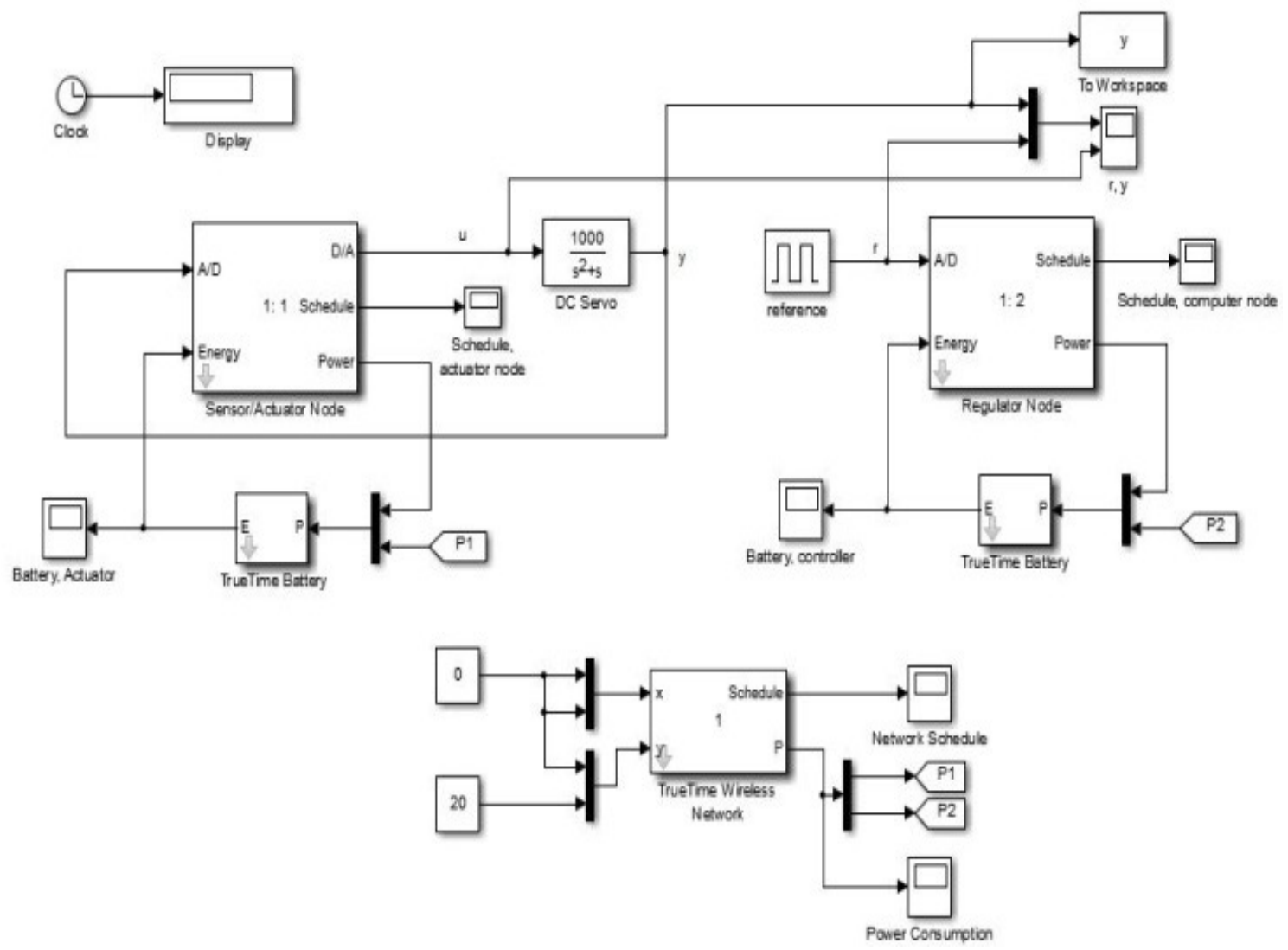

Fig. 2. Block structure of the NCS, as given in TrueTime

What follows are several graphs showing the system performance when the robust controller is implemented in different scenarios.

First and foremost, Fig. 3 shows the step response and the impulse response of the process, which makes clear the fact that we are dealing with an unstable system.
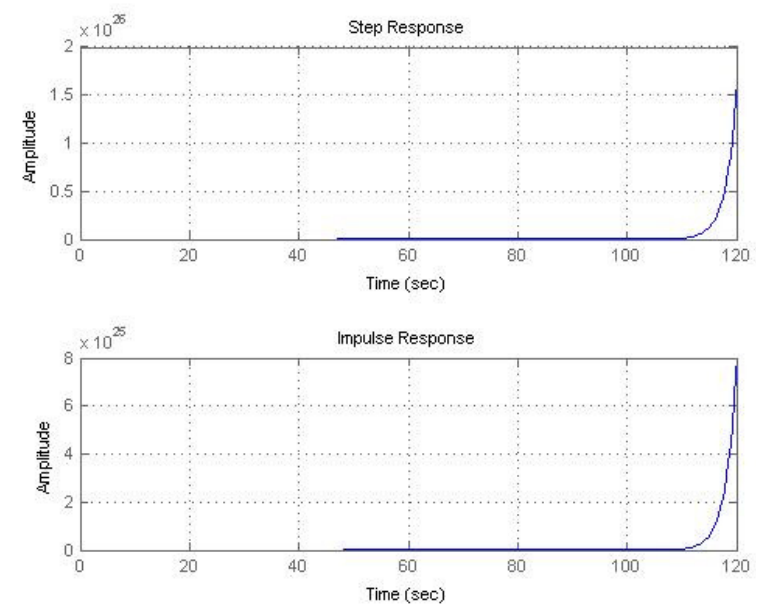

Fig. 3. Impulse and step response of the process
Next, in Fig. 4 we can see the system response when the controller is applied directly, when the network is not a part of the simulation. It is obvious that the controller has a stabilizing effect on the system, and a similar result can be seen in Fig. 5 , where the system is being controlled over the ZigBee network, but in the absence of any negative effects.

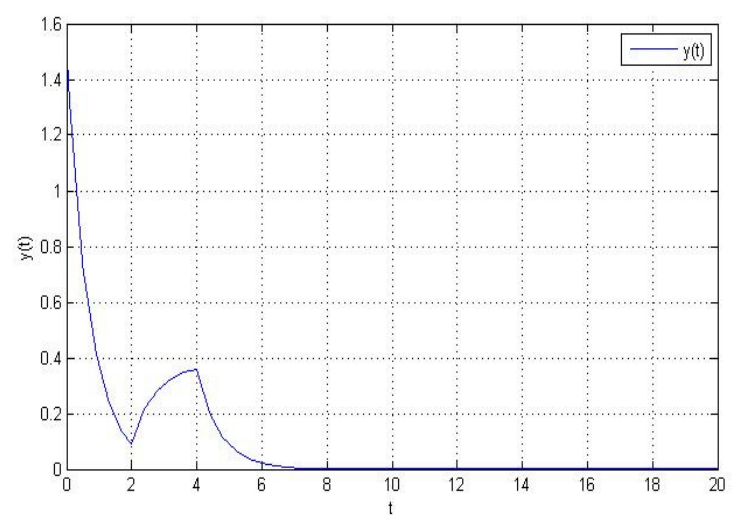

Fig. 4. Response of the controlled system without a network simulated 


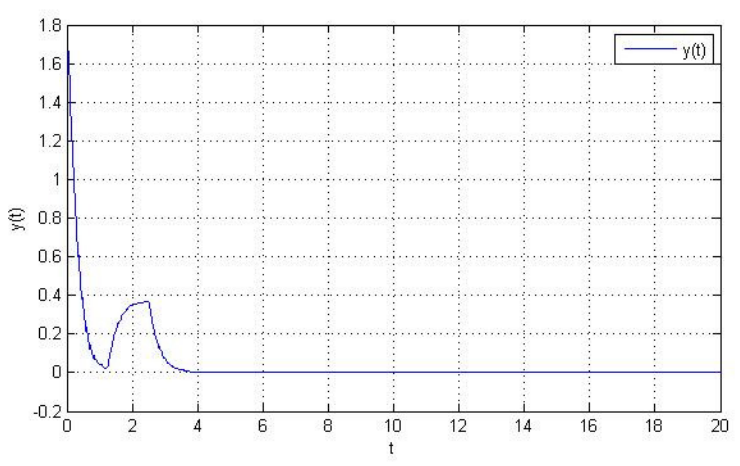

Fig. 5. Response of the NCS without any adverse effects simulated

Then, Fig. 6 shows simulation of the system performance in a situation with a probability of data loss of $25 \%$. Also, there is no sending retry, as practice has shown that in most cases the data loss is not worth the extra delay induced by the retries. Fig. 7 shows the system performance when uniform interference is applied through the network, while Fig. 8 displays the response when the random transport delays are simulated.

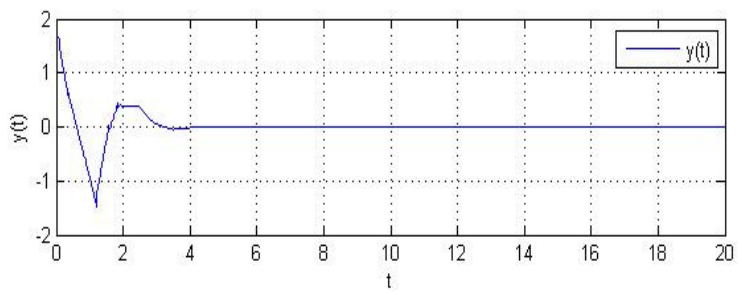

Fig. 6. Response of the NCS with $25 \%$ chance for data loss

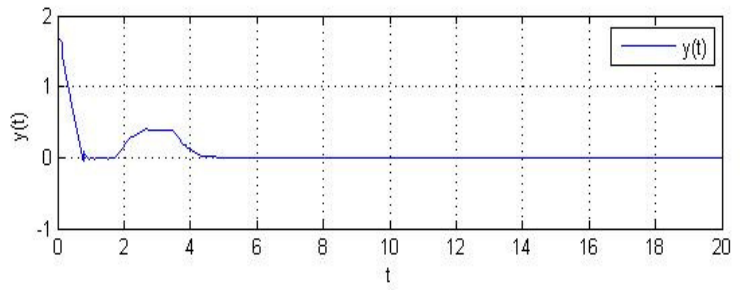

Fig. 7. Response of the NCS with uniform interference applied throughout the network

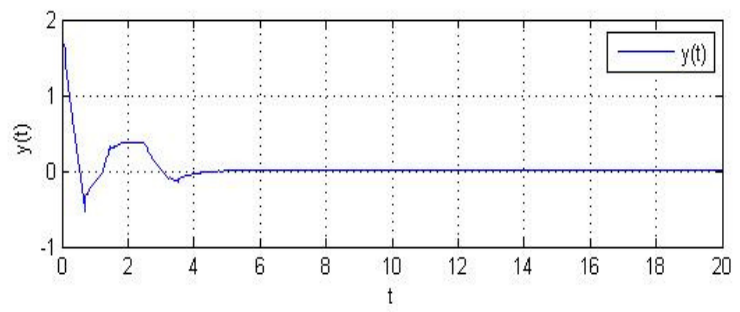

Fig. 8. Response of the NCS with random data propagation delays in the range $[0.1 \mathrm{~s} ; 0.5 \mathrm{~s}]$ simulated
It is obvious that the controller comfortably handles all the network obstructions, as the system responses conveniently converge to the stable state in all cases, only temporarily fluctuating around the $2 \mathrm{~s}-4 \mathrm{~s}$ interval, when the external perturbation is applied to the system input.

Finally, Fig. 9 shows the system performance when all previously mentioned effects were being simulated at the same time: the propagation delay, the uniform disturbance, the $25 \%$ chance of data loss, and $70 \%$ network capacity. Yet again, the $\mathrm{H}_{\infty}$ controller successfully dealt with all these effects and stabilized the system in a relatively short time.

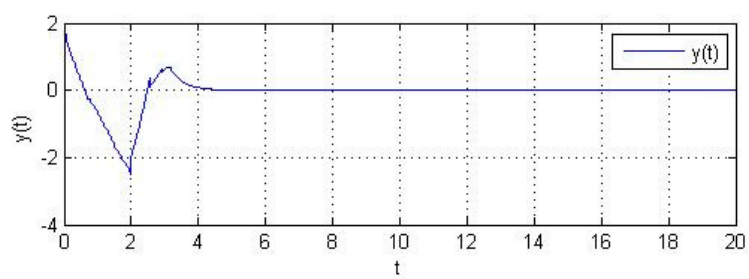

Fig. 9. Response of the NCS with $70 \%$ network capacity reduction and all other previous effects in action

Also, simulations of the system in the same conditions were made, but with different controllers applied. Fig. 10 shows the system performance under PID control (where the controller is tuned for the process without considering the network), and Fig. 11 displays the system performance with LQR control applied. Obviously, PID is unable to deal with the stochastic network occurrences, while LQR is not as effective as $\mathrm{H}_{\infty}$, but it is still successful. This can be attributed to the fact that both LQR and $\mathrm{H}_{\infty}$ have the same core and are based on the same concepts of optimal control.

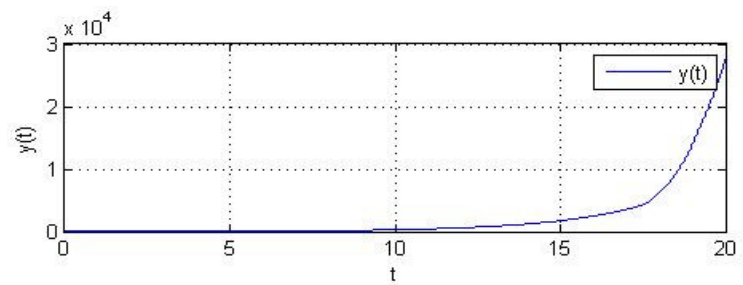

Fig. 10. NCS system response under PID control

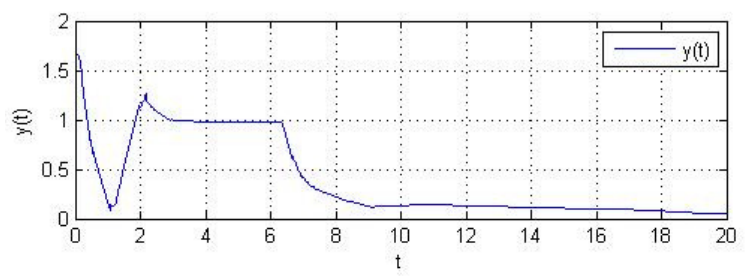

Fig. 11. NCS system response under LQR control 


\section{CONCLUSION}

In this paper, a short overview of the issues of network induced delays and data loss in networked control systems was given. Then, ZigBee was proposed as a suitable choice for a communication protocol when implementing a wireless networked control system. An overview of important implementations of this standard in networked control systems was also elaborated. Finally, an existing $\mathrm{H}_{\infty}$ control algorithm for NCS was applied to an unstable and uncertain process through a ZigBee network, and the entire system was simulated in TrueTime in different scenarios in regard to the adverse network effects.

The analysis of the simulation results implied that the controller successfully handled the negative network occurrences, and thus it can be recommended to attempt a future practical implementation of this ZigBee robust controlled NCS, which would be found useful in many applications in industry, automation, smart sensor networks, and/or home automation.

\section{REFERENCES}

[1] R. A. Gupta, M. Y. Chow: Networked Control Systems: Overview and research trends, IEEE Transactions on Industrial Electronics, pp. 2527-2535 (2010).

[2] Y. Xia, Y. Gao, L. Yan, et al.: Recent Progress in Networked Control Systems - A Survey, International Journal of Automation and Computing, 12, 4, 343-367 (2015).

[3] L. Zhang, H. Gao, O. Kaynak: Network-Induced Constraints in Networked Control Systems - A Survey, IEEE Transactions on Industrial Informatics, 9, 1, 403-416 (2013).

[4] Z. Sun, H. Li, J. Wang: Recent advances in networked control systems, International Conference on Control, Automation and Systems, Seoul, Korea, 2007.

[5] E. Kamrani, M. Mehraban: Modeling Internet delay dynamics using system identification, Proceedings of ICIT, 2006, pp. 716-721.

[6] S. Shakkottai, A. Kumar, A. Karnik, A. Anvekar: TCP performance over end-to-end rate control and stochastic available capacity, IEEE/ACM Transactions on Networking. 2001, pp. 377-391.

[7] H. Zhang, J. Yang, C. Su: T-S fuzzy-model-based robust $\mathrm{H} \infty$ design for networked control systems with uncer- tainties, IEEE Transactions on Indian Informatics, 2007, pp. 289-301.

[8] Q. Li,, D. Mills: Jitter-based delay-boundary prediction of wide area networks, IEEE/ACM Transactions on Networking, 2001 pp. 578-590,.

[9] J. Nilsson, B. Bernhardsson, B. Wittenmark: Stochastic analysis and control of real-time systems with random delays, Automatica, 34, 1, 57-64 (1998).

[10] J. Hespanha, P. Haghshtabrizi, Y. Xu: A survey of recent results in networked control systems, Proceedings of IEEE, 2007, pp. 138-162.

[11] H. Chan, U. Ozguner: Closed-loop control of systems over a communication network with queues, Int. J. Control, 62, 3, 493-510 (1995).

[12] Y. Xia, G. Liu, D. Rees: $\mathrm{H}_{\infty}$ control for networked control systems in presence of random network delay and data dropout, Proceedings of Chinese Control Conference, 2006, pp. 2030-2034.

[13] T. Tarn, N. Xi: Planning and control of internet-based teleoperation, Proceedings of SPIE: Telemanipulator and Telepresence Technologies, 1998, pp. 189-193.

[14] P. Baronti, P. Pillai, V. Chook, S. Chessa, A. Gotta, Y. F. Hu: Wireless Sensor Networks: A Survey on the State of the Art and the 802.15.4 and ZigBee Standards, Journal of Computer Communications, 30, 7, 1655-1695 (2007).

[15] G. Mouney, G. Juanole, C. Calmettes: On the implementation of one process control application type through a network considering three LANs: CAN, Wi-Fi, ZigBee, 17th OFAC World Congress, 2008.

[16] A. Koubaa, M. Alves, Y. Song, B. Nefzi: Improving the IEEE 802.15.4 slotted CSMA-CA for time-critical events in wireless sensor networks, Workshop of Real-time Networks, Satelite workshop for ECRTS, Dresden, Germany, 2006.

[17] V. Rao, D. Marandin: Adaptive backoff exponent algorithm for ZigBee, Next Generation Teletraffic and Wired/Wireless Advanced Networking, 2006, pp. 501516.

[18] J. Sobrino, A. Krishnakumar: Quality of service in ad-hoc CSMA networks, IEEE Journal on Selected Areas in Communications, 1999, pp. 1535-1568.

[19] U. Umirov, S. Jeong, J. Park: Applicability of ZigBee for real-time networked motor control systems, International Conference on Control, Automation and Systems, Seoul, Korea, 2008.

[20] D. Yue, Q. Han, J. Lam: Robust $\mathrm{H}_{\infty}$ control and filtering of networked control systems, Networked Control Systems: Theory and Applications, London: Springer, 2008, pp. 121-151.

[21] A. Cervin, M. Ohlin, D. Henriksson: Simulation of networked control systems using TrueTime, Proceedings of the 3rd International Workshop on Networked Control Systems: Tolerant to Faults, 2007. 
